\title{
Psychosocial and Behavioral Risk Profiles of Cigarette Smokers and E-Cigarette Users Among Adolescents in Minnesota: The 2016 Minnesota Student Survey
}

\author{
Tara E. Jenson, $\mathrm{MPH}^{1}$
}

\begin{abstract}
Accessible Version: www.cdc.gov/pcd/issues/2018/18_0222.htm
Suggested citation for this article: Jenson TE. Psychosocial and Behavioral Risk Profiles of Cigarette Smokers and E-Cigarette Users Among Adolescents in Minnesota: The 2016 Minnesota Student Survey. Prev Chronic Dis 2018;15:180222. DOI: https:// doi.org/10.5888/pcd15.180222.
\end{abstract}

\section{PEER REVIEWED}

\section{Abstract}

\section{Introduction}

Understanding differences in predictors of adolescent cigarette smoking and e-cigarette use can inform public health strategies for preventing and reducing tobacco use among this population. The objective of this study was to examine the association of socioeconomic, psychosocial, and behavioral factors with cigarette smoking and e-cigarette use among adolescents in Minnesota.

\section{Methods}

Records $(n=126,868)$ were used from the 2016 Minnesota Student Survey for prevalence of and factors associated with cigarette smoking and e-cigarette use among students in grades 8,9 , and 11. Logistic regression models were used to estimate risk for smoking cigarettes, using e-cigarettes, or concurrent use of both for key independent variables.

\section{Results}

American Indian students were 3.6 times as likely to report smoking cigarettes $(\mathrm{OR}=3.57 ; 95 \% \mathrm{CI}, 3.04-4.19)$, and 1.7 times as likely to report using e-cigarettes $(\mathrm{OR}=1.72 ; 95 \% \mathrm{CI}$, 1.47-2.01) as non-Hispanic white students. Bisexual students were 4 times as likely (adjusted odds ratio $[\mathrm{AOR}]=4.40 ; 95 \%$ confidence interval [CI], 4.01-4.82) as heterosexual students to smoke cigarettes and twice as likely ( $\mathrm{AOR}=2.24 ; 95 \% \mathrm{CI}, 2.06-2.43$ ) to use e-cigarettes. Students receiving free/reduced lunch were nearly twice as likely $(\mathrm{AOR}=1.92 ; 95 \% \mathrm{CI}, 1.80-2.05)$ to smoke cigarettes and 1.3 times as likely ( $\mathrm{AOR}=1.33 ; 95 \% \mathrm{CI}, 1.27-1.39$ ) to use e-cigarettes. Increasing alcohol use and decreasing academic performance were associated with increasing likelihood of cigarette smoking and e-cigarette use, more so with cigarette smoking.

\section{Conclusion}

Results expand on existing research that show differences in psychosocial and behavioral risk factors between adolescent cigarette smokers and adolescent e-cigarette users.

\section{Introduction}

E-cigarettes are a type of noncombustible tobacco product designed to allow inhalation of nicotine via vaporization of a nicotine-containing solution (1). Although the health risks of cigarette smoking are well established (2), those of e-cigarettes are largely unknown because e-cigarettes have emerged as a commercially available product in the United States only since 2007 (3). However, both the Centers for Disease Control and Prevention and the Minnesota Department of Health assert that e-cigarette use among adolescents is a health concern $(4,5)$. Rates of cigarette smoking among high school students have trended downward nationally from $15.8 \%$ in 2011 to $8.0 \%$ in 2016 (6) and in the state of Minnesota among students in grade 9 from $19.6 \%$ in 2001 to $4.3 \%$ in 2016 (5). However, the rates of e-cigarette use among high school students overall have trended upward nationally, from $1.5 \%$ in 2011 to $11.3 \%$ in 2016 , and as of 2016 was at $17.1 \%$ among 11th-grade students in Minnesota $(5,6)$.

A study in 2017 showed that prediction-model factors associated with cigarette smoking differed significantly from factors associated with e-cigarette use among adolescents in the United States (3). Regression models of key psychosocial factors that predicted 
the risk of adolescents becoming cigarette smokers approximately $75 \%$ of the time predicted adolescents becoming e-cigarette smokers only approximately $25 \%$ of the time.

Further understanding of potential differences in behavioral factors and other predictors of cigarette smoking and e-cigarette use among adolescents is critical to informing comprehensive public health strategies targeting prevention and reduction of tobacco use among this population. The objective of this study was to describe the association of key socioeconomic, psychosocial, and behavioral factors with cigarette smoking and e-cigarette use among adolescents in Minnesota.

\section{Methods}

Data for this study were sourced entirely from the 2016 Minnesota Student Survey (MSS) data set. The MSS is an anonymous, school-based, cross-sectional survey developed by 4 state agencies: the Department of Education, the Department of Health, the Department of Human Services, and the Department of Public Safety. The survey is administered every 3 years by local school districts (7). Data for the 2016 MSS were provided by public school students in Minnesota via local public school districts, and the data set is managed by the Minnesota Student Survey Interagency Team 2016 (8). The 2016 MSS data set contains 287 variables generated from approximately 112 questions on substance use, sexuality, academic performance, and other health and lifestyle behaviors and factors. The $2016 \mathrm{MSS}$ is representative of $85 \%$ of Minnesota school districts (282 of 330) and comprises completed surveys of 168,733 Minnesota public school students across grades 5, 8, 9, and 11 (9). Some questions on the 2016 MSS, including those relating to the use of alcohol, drugs, and tobacco are asked only of students in grades 8,9 , and 11 . Inquiry into sexual identity is asked only of students in grades 9 and 11 . Because this study focused on cigarette smoking and e-cigarette use, data were analyzed for students in grades 8,9 , and 11 only. Records with missing values for demographic characteristics, targeted psychosocial and behavioral-related questions, or questions on use of cigarettes, e-cigarettes, other tobacco products, or marijuana were excluded from analyses of those topics. After excluding data for students in grade 5, the total number of records analyzed for this study was 126,868 . The average age of respondents was 14.8 years (standard deviation, $1.3 \mathrm{y}$; range, 12 to 19-20 $\mathrm{y}$ [categories were whole numbers 12-18, then age 19-20]). Approval for use of the 2016 MSS data set was provided by the Minnesota Student Interagency Team (8) after institutional review board approval from the George Washington University Committee on Human Research.

\section{Variables}

For this study, 3 dependent outcome variables were created: current cigarette smokers, current e-cigarette users, and concurrent cigarette smokers and e-cigarette users. Students were categorized as current cigarette smokers if they indicated they had smoked cigarettes at least 1 day in the past 30 days by making any selection other than " 0 days" to the question "During the last 30 days, on how many days did you smoke a cigarette?" Students were categorized as current e-cigarette users if they indicated they had used e-cigarettes at least 1 day in the past 30 days by making any selection other than " 0 days" to the question "During the last 30 days, on how many days did you use an electronic cigarette (e-cigarette, e-hookah, vaping pen)?" Students were categorized as concurrent cigarette smokers and e-cigarette users if they indicated they had both smoked cigarettes and used e-cigarettes at least 1 day in the past 30 days by making any selection other than " 0 days" to both questions on cigarette smoking and e-cigarette use.

Grade level $(8,9$, or 11$)$, sex (male or female), and race/ethnicity were assessed for baseline association with cigarette smoking and e-cigarette use outcomes. For race/ethnicity, students were asked 3 questions: "Are you Hispanic or Latino(a)?," "Are you Somali?," and "Are you Hmong?" Respondents were allowed to respond yes or no or leave blank (categorized as no response). Additionally, students were asked, "What is your race?" and were allowed to choose 1 or more of the following (or leave blank): American Indian or Alaskan Native, Asian, black, African, or African American, Native Hawaiian or other Pacific Islander, or white. The MSS Interagency Team then compiled these responses into the combined variable of race/ethnicity with the following categories: American Indian non-Hispanic, Asian non-Hispanic, black nonHispanic, Pacific Islander non-Hispanic, white non-Hispanic, multiple races non-Hispanic, Hispanic, and race/ethnicity missing. Grade, sex, and race/ethnicity were then adjusted for in subsequent analysis of other independent variables because of the potential of these 3 variables as confounders that might be associated with differing cigarette and e-cigarette usage patterns, familiarity, and/or cultural norms. Only the race/ethnicity variable was used in controlling for race/ethnicity in subsequent analysis. Because of large numbers of missing responses to the questions on Hmong and Somali ethnicity, these 2 variables were excluded from the regression analysis.

The following independent socioeconomic, psychosocial, and behavioral indicator variables were analyzed for association with cigarette smoking and e-cigarette use outcomes: sexual identity (heterosexual, bisexual, gay/lesbian, not sure, or questioning), economic hardship (whether students receive free or reduced-price lunch and whether students skipped meals in the past 30 days because their family did not have enough money for food), alcohol

\footnotetext{
The opinions expressed by authors contributing to this journal do not necessarily reflect the opinions of the U.S. Department of Health and Human Services, the Public Health Service, the Centers for Disease Control and Prevention, or the authors' affiliated institutions.
} 
use in the past 30 days ( 0 days, 1 or 2 days, $3-5$ days, $6-9$ days, 10-19 days, 20-29 days, all 30 days), and academic performance (mostly As, mostly Bs, mostly Cs, mostly Ds, mostly Fs, mostly incompletes, or none of these letter grades).

\section{Statistical analysis}

Frequency analysis was conducted on the dependent variables of current cigarette smoking, e-cigarette use, and concurrent use of both as well as demographic categorical independent variables. To assess for significant association at a .05 level between each dichotomous dependent variable and the demographic, socioeconomic, psychosocial, and behavioral categorical independent variables, $\chi^{2}$ and Fisher exact test bivariate analyses were conducted.

Frequency and bivariate analyses were conducted by using IBM SPSS Statistics for Macintosh, version 24.0 (IBM Corporation); SAS software (SAS Institute Inc) surveylogistic method was used to conduct multivariate logistical regression analysis for generating odds ratios for risk of smoking cigarettes, e-cigarette use, and concurrent use of both. All independent variables included were demonstrated to be significant at a .05 level in bivariate analyses for association with smoking cigarettes, e-cigarette use, and concurrent use of both. Regression models that included grade, sex, and race/ethnicity only were used to generate baseline odds ratios for cigarette smoking, e-cigarette use, and concurrent use of both. Separate regression models for sexual identity, socioeconomic indicators, academic performance, and alcohol use, each controlling for grade, sex, and race/ethnicity were then used to generate adjusted odds ratios for cigarette smoking, e-cigarette use, and concurrent use of both. Final determination of independent variables used in regression analysis was guided by forward selection as described previously (10) in conjunction with my own interests in factors for investigation.

Small amounts of data were missing from analysis, where no answer was provided by the respondent for one or more control variables of grade, sex, and race/ethnicity, independent variables, and outcome variables. All observations for grade level contained a response. Missing data was less than $1 \%$ for sex $(\mathrm{n}=373)$ and race/ ethnicity $(\mathrm{n}=1,047), 1.2 \%(\mathrm{n}=1,521)$ for the question on free or reduced-price lunch, $2.9 \%(\mathrm{n}=3,714)$ for the question on skipped meals, $1.6 \%(\mathrm{n}=1,267)$ for the question on sexual identity, $4.9 \%$ $(\mathrm{n}=6,213)$ for the question on Somali race/ethnicity, $4.6 \%$ (n $=6,170)$ for the question on Hmong race/ethnicity, $6.9 \%(\mathrm{n}=$ $8,763)$ for the question on alcohol use, $6.9 \%(\mathrm{n}=8,760)$ for the question on e-cigarette use, and the $7.0 \%(\mathrm{n}=8,850)$ for question on cigarette smoking.

\section{Results}

The distribution of female adolescents and male adolescents was similar across grades; of 126,868 students, $49.5 \%$ were female, and $50.5 \%$ were male (Table 1). Representation of students in grade $8(35.5 \%)$ and grade $9(35.7 \%)$ was similar, whereas $28.8 \%$ of students were in grade 11 . Across all 3 grades, $1.2 \%$ of respondents were American Indian non-Hispanic, $6.0 \%$ Asian nonHispanic, 6.3\% black non-Hispanic, 7.4\% multiracial, 0.2\% Pacific Islander non-Hispanic, and $68.6 \%$ white non-Hispanic; $9.5 \%$ of respondents were Hispanic, $1.9 \%$ Somali, and $2.9 \%$ Hmong.

Of 126,868 students, 13,902 (11.0\%) reported smoking cigarettes or using e-cigarettes in the past 30 days: 5,816 students (4.6\%) reported smoking cigarettes on at least 1 day, 12,101 students $(9.5 \%)$ reported using e-cigarettes on at least 1 day, 1,801 students $(1.4 \%)$ reported smoking cigarettes only, $8,086(6.4 \%)$ reported using e-cigarettes only, and 4,015 (3.2\%) reported both smoking cigarettes and using e-cigarettes in the past 30 days.

Logistic regression analysis of grade, sex, and race/ethnicity in relation to cigarette smoking, e-cigarette use, and concurrent use of cigarettes and e-cigarettes demonstrated significant association for grade and most races/ethnicities but not for sex (Table 2). Students in grade 11 were 3.5 times as likely to report using e-cigarettes $(\mathrm{OR}=3.50 ; 95 \%$ confidence interval $[\mathrm{CI}], 3.33-3.68)$ and 3.3 times as likely to report smoking cigarettes $(\mathrm{OR}=3.34 ; 95 \%$ CI, 3.11-3.58) in the past 30 days as students in grade 8. American Indian students were 3.6 times as likely to report smoking cigarettes $(\mathrm{OR}=3.57 ; 95 \% \mathrm{CI}, 3.04-4.19)$, and 1.7 times as likely to report using e-cigarettes $(\mathrm{OR}=1.72 ; 95 \% \mathrm{CI}, 1.47-2.01)$ as non-Hispanic white students. Asian students were 0.33 times as likely to report smoking cigarettes $(\mathrm{OR}=0.33 ; 95 \% \mathrm{CI}$, $0.26-0.41$ ), and 0.47 times as likely to report using e-cigarettes $(\mathrm{OR}=0.47 ; 95 \% \mathrm{CI}, 0.41-0.54)$ as non-Hispanic white students.

Logistic regression analysis of sexual identity in relation to cigarette smoking, e-cigarette use, and concurrent use of both overall demonstrated significant association, except for gay/lesbian respondents and e-cigarette use (Table 3). Bisexual students were more than 4 times as likely (adjusted OR $[\mathrm{AOR}]=4.40 ; 95 \% \mathrm{CI}$, 4.01-4.82) as heterosexual students to smoke cigarettes but only twice as likely $(\mathrm{AOR}=2.24 ; 95 \% \mathrm{CI}, 2.06-2.43)$ to use e-cigarettes.

Logistic regression analysis of students who reported receiving free or reduced-price lunch at school or skipping meals because of economic hardship was significantly associated with increased likelihood of cigarette smoking, e-cigarette use, and concurrent use of both (Table 3). Students receiving free or reduced-price lunch were nearly twice as likely $(\mathrm{AOR}=1.92 ; 95 \% \mathrm{CI}$,

The opinions expressed by authors contributing to this journal do not necessarily reflect the opinions of the U.S. Department of Health and Human Services, the Public Health Service, the Centers for Disease Control and Prevention, or the authors' affiliated institutions. 
1.80-2.05) to smoke cigarettes but only 1.33 times as likely (AOR $=1.33 ; 95 \% \mathrm{CI}, 1.27-1.39$ ) to use e-cigarettes as students not receiving such lunch. Students reporting skipping meals were more than 3.5 times as likely $(\mathrm{AOR}=3.63 ; 95 \% \mathrm{CI}, 3.33-3.95)$ to smoke cigarettes but only 2.79 times as likely $(\mathrm{AOR}=2.79 ; 95 \%$ CI, 2.59-2.99) to use e-cigarettes as students not skipping meals.

Logistic regression analysis demonstrated significant association between academic performance and cigarette smoking, e-cigarette use, and concurrent use of both (Table 3). Students reporting mostly Bs were more than twice as likely $(\mathrm{AOR}=2.47 ; 95 \% \mathrm{CI}$, 2.25-2.7) to have smoked cigarettes in the past 30 days and nearly twice as likely $(\mathrm{AOR}=1.91 ; 95 \% \mathrm{CI}, 1.80-2.01)$ to have used ecigarettes in the past 30 days as students reporting that they receive mostly As. Students reporting mostly Fs were 8 times as likely $(\mathrm{AOR}=8.08 ; 95 \% \mathrm{CI}, 6.81-9.59)$ to smoke cigarettes but only 3.64 times as likely $(\mathrm{AOR}=3.64 ; 95 \% \mathrm{CI}, 3.16-4.19)$ to use e-cigarettes as students reporting mostly As.

Logistic regression analysis yielded significant association levels of alcohol use and cigarette smoking, e-cigarette use and concurrent use of both, demonstrating the highest odds ratios, compared with any variable analyzed for this study, for each category of alcohol use, even at the lowest level of 1 or 2 days (Table 3). The odds ratios for concurrent cigarette and e-cigarette use were larger across all categories of alcohol use than for cigarette smoking and e-cigarette use alone. Odds ratios for 1 or 2 days of drinking were similar for cigarettes $(\mathrm{AOR}=9.79 ; 95 \% \mathrm{CI}, 9.08-10.56)$ and e-cigarettes $(\mathrm{AOR}=9.25$; CI 95\% 8.78, 9.75) but higher for concurrent cigarette and e-cigarette use $(\mathrm{AOR}=11.3 ; 95 \% \mathrm{CI}$ 10.3-12.4). Odds ratios increased more steeply at higher levels of alcohol use for cigarette smoking than for e-cigarette use.

\section{Discussion}

Although the potential health harms of e-cigarettes are under study and yet largely unknown (3), investigation into patterns of e-cigarette use among adolescents, particularly when patterns diverge from those of cigarette smoking among adolescents, is an important priority for public health agencies. The Centers for Disease Control and Prevention and other public health agencies consider e-cigarette use among adolescents a public health concern $(5,6)$, and one goal of Healthy People 2020 is the reduction of tobacco use among adolescents (11). Additionally, although e-cigarettes contain no tobacco, they are regulated by the US Food and Drug Administration as tobacco products because of their nicotine content (12).

This study adds to research (3) highlighting significant differences in psychosocial and behavioral risk factors predicting cigarette smoking and e-cigarette use among adolescents. This analysis showed significant associations between independent variables (sexual identity, socioeconomic indicators, alcohol use, and academic performance) and the outcomes of cigarette smoking and ecigarette use. It also suggests that differences exist in the magnitude of risk for cigarette smoking or e-cigarette use for some categories of sexual identity, economic status, school performance, and alcohol use. For example, bisexual students, students reporting mostly Fs, and students reporting alcohol use 10 or more days in the past 30 days were at least twice as likely to smoke cigarettes as e-cigarettes. Further analysis should test these differences. Also of interest was that although in this sample of adolescents in Minnesota the prevalence of cigarette smoking (4.6\%) was approximately half that of e-cigarette use $(9.5 \%)$, the odds ratios for cigarette smoking were greater than for e-cigarette use across all categories of the independent variables analyzed. Ideally, further research will shed more light on the various risk factors for cigarette smoking and e-cigarette use among adolescents as well as on the health risks of e-cigarette use among this population. Such research would allow public health practitioners to more effectively target tobacco-reduction interventions by differentiating between cigarette smokers and e-cigarette users and determining which group may be at higher risk for harmful health outcomes.

This study has numerous limitations and opportunities for further analysis. One limitation was the extent of missing data. Missing data for demographic, independent, and outcome variables ranged from less than $1 \%$ for the question on sex $(n=373)$ to $6.9 \%(n=$ $8,760)$ for using e-cigarettes and $7.0 \%(n=8,850)$ for cigarette smoking. For a sample size of 126,868 , these are relatively small amounts. However, when comparing these numbers to the numbers of students who reported smoking $(n=5,816$ or $4.6 \%)$ or using e-cigarettes $(n=12,101$ or $9.5 \%)$, the extent of missing data is more relevant. Additionally, given that Minnesota is home to an estimated 40,000 people of Somali origin (13), 70,000 people of Hmong ethnicity (13), and 288,000 people of Hispanic or Latino ethnicity (13), having further insight into patterns of tobacco use among adolescents in these populations would be valuable to public health practitioners. If time had permitted, I would have conducted a more in-depth and systematic investigation into the reasons for missing data and how to account for them.

Another limitation of this study is use of a single cross-sectional survey. Given further time and a more robust study design, it would be worth conducting regression analyses separately across multiple years of the MSS. One opportunity for a more robust analysis of the MSS data set would be an investigation into the increased prevalence of cigarette smoking and e-cigarette use with each successive grade level. This investigation would include run-

The opinions expressed by authors contributing to this journal do not necessarily reflect the opinions of the U.S. Department of Health and Human Services, the Public Health Service, the Centers for Disease Control and Prevention, or the authors' affiliated institutions. 
ning separate regression analyses by grade rather than controlling for grade as well as developing an all-inclusive regression model for all variables.

One strength of this study is having used the MSS. Although studies of data from the National Youth Tobacco Survey (14) and the Minnesota Youth Tobacco Survey (15) provide a more robust inquiry into the home, environment, and exposure characteristics of adolescent smokers, both surveys have smaller sample sizes (20,675 in 2016 and 4,243 in 2014, respectively) that limit utility of extracting data on racial/ethnic and geographic characteristics $(16,17)$. The larger sample size of the MSS potentially allows for a more robust analysis of racial/ethnic and geographic characteristics and an inquiry into a broader range of socioeconomic and behaviors.

This study adds to research indicating that socioeconomic and behavioral risk factors differ between students who smoke cigarettes and students who use e-cigarettes, further suggesting that public health outreach programs to reduce tobacco use among adolescents may need to differ in methods and messages, with program choices depending on the risk factors of the target audience and whether the goal is to reduce cigarette smoking or reduce e-cigarette use.

\section{Acknowledgments}

I received no financial support for this work and used no copyrighted materials. Data for the 2016 MSS was provided by public school students in Minnesota via local public school districts, and the data set is managed by the Minnesota Student Survey Interagency Team 2016. I thank the students of Minnesota for providing data to the MSS, the Minnesota Student Survey Interagency Team for allowing use of the MSS data set, and the Minnesota Department of Health Asthma Program for initially acquainting me with the MSS data set.

\section{Author Information}

Corresponding Author: Tara E. Jenson, MPH, 1914 Newton Ave N, Minneapolis, MN 55411. Telephone: 612-581-5527. Email: tara.e.jenson@gmail.com.

Author Affiliations: ${ }^{1}$ Milken Institute School of Public Health, The George Washington University, Washington, DC.

\section{References}

1. Goniewicz ML, Knysak J, Gawron M, Kosmider L, Sobczak A, Kurek J, et al. Levels of selected carcinogens and toxicants in vapour from electronic cigarettes. Tob Control 2014; 23(2):133-9.

2. Centers for Disease Control and Prevention. Smoking \& tobacco use. 2017. https://www.cdc.gov/tobacco/data statistics/fact_sheets/health_effects/effects_cig_smoking/ index.htm. Accessed August 14, 2017.

3. Dutra LM, Glantz SA. E-cigarettes and national adolescent cigarette use: 2004-2014. Pediatrics 2017;139(2):e20162450.

4. Centers for Disease Control and Prevention. E-cigarettes and young people: a public health concern. 2017. https:// www.cdc.gov/features/ecigarettes-young-people/index.html. Accessed August 14, 2017.

5. Minnesota Department of Health. The health of adolescents: early results from the 2016 Minnesota Student Survey. 2016. http://www.health.state.mn.us/divs/chs/mss/Health-related fact_sheet_MSS_2016_10-31-16.pdf. Accessed July 24, 2017.

6. Jamal A, Gentzke A, Hu SS, Cullen KA, Apelberg BJ, Homa DM, et al. Tobacco use among middle and high school students - United States, 2011-2016. MMWR Morb Mortal Wkly Rep 2017;66(23):597-603.

7. Minnesota Department of Education. Minnesota Student Survey. Minnesota Student Survey frequently asked questions. 2018. https://education.mn.gov/mde/dse/health/mss/ MDE059027. Accessed June 4, 2018.

8. Minnesota Student Survey Interagency Team. 2016. Roseville (MN): Minnesota Department of Education, 2016.

9. Minnesota Department of Education. Minnesota Department of Education. Minnesota Student Survey. 2016. http:// education.state.mn.us/MDE/dse/health/mss/. Accessed August 14, 2017.

10. Bursac Z, Gauss CH, Williams DK, Hosmer DW. Purposeful selection of variables in logistic regression. Source Code Biol Med 2008;3(1):17.

11. Centers for Disease Control and Prevention. National Youth Tobacco Survey (NYTS). 2018. https://www.cdc.gov/tobacco/ data_statistics/surveys/nyts/index.htm. Accessed June 15, 2018.

12. Palazzolo DL. Electronic cigarettes and vaping: a new challenge in clinical medicine and public health. A literature review. Front Public Health 2013;1:56.

13. US Census Bureau. American fact finder: your geography selections. 2015. https://factfinder.census.gov/faces/ tableservices/jsf/pages/productview.xhtml?pid=ACS_15_SPT_ B01003\&prodType=table. Accessed November 13, 2017.

14. Dutra LM, Glantz SA. E-cigarettes and national adolescent cigarette use: 2004-2014. Pediatrics 2017;139(2):e20162450.

15. Minnesota Department of Health. Tobacco prevention and control. Data and reports. 2018. http://www.health.state.mn.us/ divs/hpcd/tpc/data.html. Accessed July 15, 2018.

The opinions expressed by authors contributing to this journal do not necessarily reflect the opinions of the U.S. Department of Health and Human Services, the Public Health Service, the Centers for Disease Control and Prevention, or the authors' affiliated institutions. 
16. Jamal A, Gentzke A, Hu SS, Cullen KA, Apelberg BJ, Homa $\mathrm{DM}$, et al. Tobacco use among middle and high school students - United States, 2011-2016. MMWR Morb Mortal Wkly Rep 2017;66(23):597-603.

17. Minnesota Department of Health. Teens and tobacco in Minnesota, 2014 update. http:/www.health.state.mn.us/divs/ chs/tobacco/teenstobaccodata110714.pdf. Accessed July 24, 2017. 


\section{Tables}

Table 1. Prevalence of Cigarette Smoking and E-Cigarette Use in the Past 30 Days, by Selected Demographic, Socioeconomic and Behavioral Characteristics Among Adolescents in Minnesota ( $\mathrm{N}=126,868$ ), Minnesota Student Survey, $2016^{\mathrm{a}}$

\begin{tabular}{|c|c|c|c|c|}
\hline Variable & $\begin{array}{l}\text { Total, No. }(\%) \\
(\mathrm{N}=126,868)\end{array}$ & $\begin{array}{l}\text { Cigarettes, No. (\%) } \\
\quad(n=5,816)\end{array}$ & $\begin{array}{l}\text { E-Cigarettes, No. }(\%) \\
\quad(n=12,101)\end{array}$ & $\begin{array}{l}\text { Both Cigarettes and E- } \\
\text { Cigarettes, No. }(\%)(n=4,015)\end{array}$ \\
\hline \multicolumn{5}{|l|}{ Grade level } \\
\hline Grade 8 & $44,983(35.5)$ & $1,176(20.2)$ & 2,412 (19.9) & 776 (19.3) \\
\hline Grade 9 & $45,309(35.7)$ & $1,787(30.7)$ & $3,891(32.2)$ & $1,236(30.8)$ \\
\hline Grade 11 & $35,576(28.8)$ & 2,853 (49.1) & $5,798(47.9)$ & 2,003 (49.9) \\
\hline \multicolumn{5}{|l|}{ Sex } \\
\hline Male & $63,818(50.5)$ & $2,738(47.1)$ & $6,328(52.3)$ & $1,976(49.2)$ \\
\hline Female & $62,677(49.5)$ & $3,064(52.7)$ & $5,747(47.5)$ & $2,030(50.6)$ \\
\hline \multicolumn{5}{|l|}{ Race/ethnicity ${ }^{b}$} \\
\hline American Indian & $1,516(1.2)$ & $188(3.2)$ & $203(1.7)$ & $104(2.6)$ \\
\hline Asian & 7,551 (6.0) & $128(2.2)$ & 361 (3.0) & $89(2.2)$ \\
\hline Black & $8,052(6.3)$ & $213(3.7)$ & $488(4.0)$ & $149(3.7)$ \\
\hline Hispanic & $12,040(9.5)$ & $652(11.2)$ & 1,402 (11.6) & $451(11.2)$ \\
\hline Multiple races & $9,372(7.4)$ & 640 (11.0) & 1,196 (9.9) & 439 (10.9) \\
\hline Pacific Islander & $207(0.2)$ & $14(0.2)$ & $25(0.2)$ & $11(0.3)$ \\
\hline White & $87,083(68.6)$ & 3,949 (67.9) & $8,351(69.0)$ & $2,747(68.4)$ \\
\hline Somali ${ }^{c}$ & 2,406 (1.9) & $88(1.5)$ & 137 (1.1) & $71(1.8)$ \\
\hline Hmong $^{c}$ & 3,631 (2.9) & $92(1.6)$ & $213(1.8)$ & $65(1.6)$ \\
\hline \multicolumn{5}{|l|}{ Sexual identity ${ }^{d}$} \\
\hline Heterosexual & 72,305 (89.7) & 3,506 (76.3) & $8,256(85.9)$ & $2,462(76.7)$ \\
\hline Bisexual & $4,014(5.0)$ & $727(15.8)$ & $860(9.0)$ & $502(15.6)$ \\
\hline Gay or lesbian & $1,027(1.3)$ & $128(2.8)$ & $167(1.7)$ & $85(2.7)$ \\
\hline Not sure or questioning & $3,272(4.1)$ & $233(5.1)$ & $324(3.4)$ & $160(5.0)$ \\
\hline \multicolumn{5}{|l|}{ Economic status } \\
\hline $\begin{array}{l}\text { Receives free or reduced-price } \\
\text { lunch }\end{array}$ & $35,663(28.5)$ & $2,344(40.5)$ & $3906(32.4)$ & $1564(39.2)$ \\
\hline $\begin{array}{l}\text { In past } 30 \text { days, skipped meals } \\
\text { because family did not have } \\
\text { enough money to buy food }\end{array}$ & $5,700(4.6)$ & 866 (15.0) & 1,269 (10.5) & $620(15.6)$ \\
\hline \multicolumn{5}{|l|}{ Grades reported $^{e}$} \\
\hline Mostly As & 54914 (43.8) & $763(13.3)$ & $2,515(21.1)$ & $484(12.2)$ \\
\hline Mostly Bs & $43,702(34.9)$ & $1,910(33.3)$ & $4,576(38.3)$ & 1,307 (33.0) \\
\hline Mostly Cs & 19,125 (15.3) & $1,865(32.5)$ & $3,245(27.2)$ & $1,330(33.5)$ \\
\hline
\end{tabular}

\footnotetext{
${ }^{a}$ Numbers do not total expected value because of missing data. Percentages are based on n's in column head.

${ }^{\mathrm{b}}$ All categories are non-Hispanic, except Hispanic.

${ }^{\mathrm{c}}$ Somali and Hmong race/ethnicity asked about as a yes-or-no question separately from the question on race.

${ }^{\mathrm{d}}$ Sexual identity inquired of grades 9 and 11 only.

e Numbers may not total expected value because of a small number of responses of "mostly incompletes" or "none of these letter grades."
} 
(continued)

Table 1. Prevalence of Cigarette Smoking and E-Cigarette Use in the Past 30 Days, by Selected Demographic, Socioeconomic and Behavioral Characteristics Among Adolescents in Minnesota ( $N=126,868)$, Minnesota Student Survey, $2016^{a}$

\begin{tabular}{|c|c|c|c|c|}
\hline Variable & $\begin{array}{l}\text { Total, No. }(\%) \\
(\mathrm{N}=126,868)\end{array}$ & $\begin{array}{l}\text { Cigarettes, No. (\%) } \\
\quad(n=5,816)\end{array}$ & $\begin{array}{l}\text { E-Cigarettes, No. (\%) } \\
\quad(n=12,101)\end{array}$ & $\begin{array}{l}\text { Both Cigarettes and E- } \\
\text { Cigarettes, No. }(\%)(n=4,015)\end{array}$ \\
\hline Mostly Ds & $4,483(3.6)$ & $682(11.9)$ & $982(8.2)$ & $486(12.3)$ \\
\hline Mostly Fs & $1,716(1.4)$ & $354(6.2)$ & $420(3.52)$ & $238(6.0)$ \\
\hline \multicolumn{5}{|c|}{ No. of days of alcohol use in past 30 days } \\
\hline 0 & $101,737(86.1)$ & $1,777(30.8)$ & $4,946(41.2)$ & $1,010(25.4)$ \\
\hline 1 or 2 & $9,931(8.4)$ & $1,612(28.0)$ & $3,416(28.5)$ & $1,096(27.5)$ \\
\hline $3-5$ & $3,519(3.0)$ & $1,062(18.4)$ & $1,838(15.3)$ & $824(20.7)$ \\
\hline $6-9$ & $1,613(1.4)$ & $663(11.5)$ & $1,002(8.4)$ & $522(13.1)$ \\
\hline $10-19$ & $811(0.7)$ & $441(7.7)$ & $537(4.5)$ & $357(9.0)$ \\
\hline $20-29$ & $205(0.2)$ & $111(1.9)$ & $129(1.1)$ & $90(2.3)$ \\
\hline All 30 & $289(0.2)$ & $102(1.8)$ & 130 (1.1) & $83(2.1)$ \\
\hline
\end{tabular}

${ }^{\text {a }}$ Numbers do not total expected value because of missing data. Percentages are based on n's in column head.

${ }^{\mathrm{b}}$ All categories are non-Hispanic, except Hispanic.

${ }^{\mathrm{c}}$ Somali and Hmong race/ethnicity asked about as a yes-or-no question separately from the question on race.

${ }^{\mathrm{d}}$ Sexual identity inquired of grades 9 and 11 only.

e Numbers may not total expected value because of a small number of responses of "mostly incompletes" or "none of these letter grades." 
Table 2. Crude Odds Ratios for Cigarette Smoking and E-Cigarette Use in the Past 30 Days, by Selected Demographic Characteristics Among Adolescents in Minnesota $(\mathrm{N}=126,868)$, Minnesota Student Survey, 2016

\begin{tabular}{|c|c|c|c|c|c|c|}
\hline \multirow{2}{*}{$\begin{array}{l}\text { Demographic } \\
\text { Characteristic }\end{array}$} & \multicolumn{2}{|c|}{ Cigarettes } & \multicolumn{2}{|c|}{ E-cigarettes } & \multicolumn{2}{|c|}{ Both Cigarettes and E-Cigarettes } \\
\hline & Crude $\mathrm{OR}^{\mathrm{a}}(95 \% \mathrm{Cl})$ & $P$ Value $^{\mathrm{b}}$ & Crude $\mathrm{OR}^{\mathrm{a}}(95 \% \mathrm{Cl})$ & $P$ Value $^{\mathrm{b}}$ & Crude $\mathrm{OR}^{\mathrm{a}}(95 \% \mathrm{Cl})$ & $P$ Value $^{\mathrm{b}}$ \\
\hline \multicolumn{7}{|l|}{ Grade level } \\
\hline Grade 8 & 1.0 [Reference] & NA & 1.0 [Reference] & NA & 1.0 [Reference] & NA \\
\hline Grade 9 & $1.58(1.46-1.70)$ & $<.001$ & $1.71(1.62-1.80)$ & $<.001$ & $1.64(1.50-1.80)$ & $<.001$ \\
\hline Grade 11 & $3.34(3.11-3.58)$ & $<.001$ & $3.50(3.33-3.68)$ & $<.001$ & $3.47(3.19-3.77)$ & $<.001$ \\
\hline \multicolumn{7}{|l|}{$\operatorname{Sex}^{\mathrm{c}}$} \\
\hline Male & 1.0 [Reference] & NA & 1.0 [Reference] & NA & 1.0 [Reference] & NA \\
\hline Female & $1.11(1.01-1.17)$ & .80 & $0.88(0.84-0.91)$ & .42 & $1.01(0.95-1.08)$ & .97 \\
\hline \multicolumn{7}{|l|}{ Race/ethnicity ${ }^{d}$} \\
\hline American Indian & $3.57(3.04-4.19)$ & $<.001$ & $1.72(1.47-2.01)$ & $<.001$ & $2.65(2.15-3.26)$ & $<.001$ \\
\hline Asian & $0.33(0.26-0.41)$ & $<.001$ & $0.47(0.41-0.54)$ & $<.001$ & $0.33(0.25-0.43)$ & $<.001$ \\
\hline Black & $0.67(0.57-0.72)$ & $<.001$ & $0.81(0.73-0.91)$ & $<.001$ & $0.64(0.52-0.78)$ & $<.001$ \\
\hline Hispanic & $1.37(1.25-1.49)$ & .001 & $1.45(1.37-1.55)$ & $<.001$ & $1.36(1.23-1.51)$ & .003 \\
\hline Multiple races & $1.74(1.60-1.90)$ & $<.001$ & $1.59(1.49-1.70)$ & $<.001$ & $1.70(1.53-1.89)$ & $<.001$ \\
\hline Pacific Islander & $1.72(0.98-3.01)$ & .09 & $1.47(0.94-2.30)$ & .15 & $1.94(1.03-3.63)$ & .05 \\
\hline White & 1.0 [Reference] & NA & 1.0 [Reference] & $\mathrm{NA}$ & 1.0 [Reference] & NA \\
\hline Somali ${ }^{\mathrm{e}}$ & $1.40(1.07-1.83)$ & .007 & $0.93(0.76-1.15)$ & .43 & $1.68(1.24-2.28)$ & $<.001$ \\
\hline Hmong ${ }^{\mathrm{e}}$ & $1.43(1.07-1.90)$ & .09 & $1.15(0.95-1.40$ & .14 & $1.47(1.05-2.05)$ & .14 \\
\hline
\end{tabular}

Abbreviations: $\mathrm{Cl}$, confidence interval; $\mathrm{NA}$, not applicable; OR, odds ratio.

${ }^{a}$ Crude ORs calculated by using a logistic regression model for grade, sex, and race/ethnicity.

${ }^{\mathrm{b}}$ Significant at $P=.05$.

" Numbers do not total expected value because of a small portion of responses of "no answer" to the question, "what is your biological sex?"

d All categories are non-Hispanic, except Hispanic. Percentages for racial or ethnic categories of American Indian, Asian, black, Hispanic, multiple races, Pacific Islander, and white do not total 100 because of a small portion of responses of "no answer."

e Somali and Hmong race/ethnicity asked about as a yes-or-no question separately from the question on race; reference group for each is "no response." 
Table 3. Adjusted Odds Ratios for Cigarette Smoking and E-Cigarette Use in the Past 30 Days, by Selected Socioeconomic and Behavioral Characteristics Among Adolescents in Minnesota ( $N=126,868$ ), Minnesota Student Survey, 2016

\begin{tabular}{|c|c|c|c|c|c|c|}
\hline \multirow[b]{2}{*}{ Risk Factor } & \multicolumn{2}{|l|}{ Cigarettes } & \multicolumn{2}{|l|}{ E-Cigarettes } & \multicolumn{2}{|c|}{ Both Cigarettes and E-Cigarettes } \\
\hline & Adjusted $\mathrm{OR}^{\mathrm{a}}(95 \% \mathrm{Cl})$ & $P$ Value $^{\mathrm{b}}$ & Adjusted OR ${ }^{\mathrm{a}}(95 \% \mathrm{Cl})$ & $P$ Value $^{\mathrm{b}}$ & Adjusted OR ${ }^{\mathrm{a}}(95 \% \mathrm{Cl})$ & $P$ Value $^{\mathrm{b}}$ \\
\hline \multicolumn{7}{|l|}{ Sexual identity ${ }^{c}$} \\
\hline Heterosexual (straight) & 1.0 [Reference] & NA & 1.0 [Reference] & NA & 1.0 [Reference] & NA \\
\hline Bisexual & $4.40(4.01-4.82)$ & $<.001$ & $2.24(2.06-2.43)$ & $<.001$ & $4.22(3.79-4.69)$ & $<.001$ \\
\hline Gay/lesbian & $2.75(2.27-3.34)$ & .001 & $1.48(1.24-1.76)$ & .19 & $2.52(2.00-3.17)$ & .03 \\
\hline \multicolumn{7}{|l|}{ Economic status $^{\mathrm{d}}$} \\
\hline Receives free or reduced-price lunch & $1.92(1.80-2.05)$ & $<.001$ & $1.33(1.27-1.39)$ & $<.001$ & $1.77(1.64-1.91)$ & $<.001$ \\
\hline $\begin{array}{l}\text { In last } 30 \text { days, skipped meals because family } \\
\text { did not have enough money to buy food }\end{array}$ & $3.63(3.33-3.95)$ & $<.001$ & $2.79(2.59-2.99)$ & $<.001$ & $3.70(3.35-4.08)$ & $<.001$ \\
\hline \multicolumn{7}{|l|}{ Grades reported } \\
\hline Mostly As & 1.0 [Reference] & NA & 1.0 [Reference] & NA & 1.0 [Reference] & NA \\
\hline Mostly Bs & $2.47(2.25-2.70)$ & $<.001$ & $1.91(1.80-2.01)$ & $<.001$ & $2.63(2.35-2.94)$ & $<.001$ \\
\hline Mostly Cs & $4.58(4.14-5.07)$ & $<.001$ & $2.75(2.58-2.94)$ & $<.001$ & $4.93(4.36-5.58)$ & $<.001$ \\
\hline Mostly Ds & $5.89(5.16-6.72)$ & $<.001$ & $3.10(2.81-3.41)$ & $<.001$ & $6.11(5.24-7.14)$ & $<.001$ \\
\hline Mostly Fs & $8.08(6.81-9.59)$ & $<.001$ & $3.64(3.16-4.19)$ & $<.001$ & $7.42(6.08-9.06)$ & $<.001$ \\
\hline \multicolumn{7}{|l|}{ No. of days of alcohol use in past 30 days } \\
\hline 0 & 1.0 [Reference] & NA & 1.0 [Reference] & NA & 1.0 [Reference] & NA \\
\hline 1 or 2 & $9.79(9.08-10.6)$ & $<.001$ & $9.25(8.78-9.75)$ & $<.001$ & $11.3(10.3-12.4)$ & $<.001$ \\
\hline $3-5$ & $21.5(19.6-23.5)$ & .01 & $18.7(17.3-20.1)$ & $<.001$ & $27.4(24.7-30.5)$ & $<.001$ \\
\hline $6-9$ & $34.5(30.7-38.7)$ & $<.001$ & $27.5(24.7-30.7)$ & $<.001$ & $42.5(37.3-48.3)$ & $<.001$ \\
\hline $10-19$ & $61.6(52.9-71.7)$ & $<.001$ & $34.4(29.5-40.2)$ & $<.001$ & $72.0(61.4-84.3)$ & $<.001$ \\
\hline $20-29$ & $68.4(50.8-92.0)$ & $<.001$ & $34.3(25.2-46.8)$ & $<.001$ & 78.7 (58.5-106.0) & $<.001$ \\
\hline All 30 & $31.2(24.0-40.6)$ & $<.001$ & $15.2(11.8-19.7)$ & .33 & $40.0(30.3-52.7)$ & $<.001$ \\
\hline
\end{tabular}

Abbreviations: $\mathrm{Cl}$, confidence interval; NA, not applicable; OR, odds ratio.

${ }^{a}$ Adjusted ORs calculated by using a logistic regression model adjusted for grade, sex, and race/ethnicity.

${ }^{\mathrm{b}}$ Significant at $P=.05$.

${ }^{c}$ Sexual identity inquired of grades 9 and 11 only.

${ }^{\mathrm{d}}$ Reference group is students who responded no. 